\title{
Mapping the mindsponge model onto the current understanding of how children learn
}

\author{
Ho Manh Tung \\ Ritsumeikan Asia Pacific University \\ Beppu, Oita, Japan,
}

September 11, 2020

I often hear people say about children: "They learn like a sponge." It is clear young brains have a lot more neuroplasticity, which makes it easier for them to learn. But we know from decades of research on neuroplasticity, the capacity for the brain to change and adapt to new situations is there for a lifetime. Neuroscientist David Eagleman titled his most recent book "Livewired" to describe this lifelong capacity of the brain (2020).

We live in a world where there is no shortage of new information, new books to read, new online courses to take, new scientific and technological revolutions to witness (Leroi et al., 2020). And as for work, it is hard to imagine anyone doing the same thing for the rest of their lives in this new reality. Thus, the ability to learn new skills and to adopt new beliefs and norms when necessary is crucial to survive and thrive in the modern digital era.

In the literature of artificial intelligence (AI), the scariest kind of AI is the kind of AI that figures out the source code of learning, which means it not only learns better than 
humans, but it learns how to learn better than humans (Bostrom, 2014). So how do normal humans learn better? I guess the starting point is all about having a good model of learning.

Here, it is worth looking at the literature of developmental psychology to understand why children, the best learning machines, learn so effectively and quickly about the world around them. The current best understanding of how children learn is a combination of probabilistic models and Bayesian inference: babies seem to have intuitive models of the world, which allows them to make a lot of predictions. Then they test these predictions using their interactions with and observations of the world. These informal experiments and statistics allow them to further fine-tune their intuitive physic and social models (Gopnik, 2012).

How do we map this understanding onto real-world learning? Instead of using words such as probability, experimentations, models, etc., we should be using beliefs, emotions, cognitions, behaviors. Learning is about changing your beliefs, attitudes, and behaviors. Updating your representation of the world is a fancy way of saying modifying beliefs and attitudes in light of new information.

In the mindsponge model, the mind is analogized to a sponge that squeezes out unsuitable values and absorbs new ones that are compatible with its core value (Vuong, 2016; Vuong \& Napier, 2015). The authors have extensively discussed the mindsponge process in the context of acculturation and talk about it in terms of values addition and subtraction. But I believe it can be expanded to talk about learning and information: how does a mindsponge filter out information? How does it absorb new information? How does this process repeat? 
In the traditional $\mathrm{ABC}$ (affect, behavior, cognition) model of behavioral changes: for a positive change to last, a person must not only think in a new way but also changes the way he or she feels and acts accordingly (Breckler, 1984). This is the reason why children learn so effectively and quickly, because they don't merely absorb new information, but they incorporate the new information into their emotional and behavioral modalities. Arguably, once children really learn a new thing, they effectively forget that they have learned it, and the new way of seeing the world or of speaking a certain way has become natural.

The mindsponge model enables another way to look at this process. First, to learn something new, one must be open to new information. Thus, the mind must not be rigid. Then, once the mind is exposed to new information, to reach the point when it has effectively learned a new way of thinking and being; this information must be "squeezed out" in the form of emotions and actions. This is the unlearning process: to make what we have learned a part of the core of one's being, that we not have to think about it anymore.

\section{References}

Bostrom, N. (2014). Superintelligence: Paths, dangers, strategies. London: Oxford University Press.

Breckler, S. J. (1984). Empirical validation of affect, behavior, and cognition as distinct components of attitude. Journal of Personality and Social Psychology, 47(6), 1191. 
Eaglemen, D. (2020). Livewired: The inside story of the ever-changing brain. London: Pantheon Books.

Gopnik, A. (2012). Scientific thinking in young children: Theoretical advances, empirical research, and policy implications. Science, 337(6102), 1623-1627.

Leroi, A. M., Lambert, B., Mauch, M., Papadopoulou, M., Ananiadou, S., Lindberg, S. I., \& Lindenfors, P. (2020). On revolutions. Palgrave Communications, 6(1), 4. doi:10.1057/s41599-019-0371-1

Vuong, Q. H. (2016). Global mindset as the integration of emerging socio-cultural values through mindsponge processes: A transition economy perspective. In: J. Kuada (ed.) Global Mindsets: Exploration and Perspectives (pp. 109-126). Routledge, UK.

Vuong, Q.H., Napier, N.K. (2015). Acculturation and global mindsponge: an emerging market perspective. International Journal of Intercultural Relations 49, 354-367. 